\title{
Erratum to: The Construct Validity of the Illness Cognition Questionnaire: The Robustness of the Three-factor Structure Across Patients with Chronic Pain and Chronic Fatigue
}

Emelien Lauwerier • Geert Crombez •

Stefaan Van Damme • Liesbet Goubert •

Dirk Vogelaers • Andrea W. M. Evers

Published online: 13 November 2009

(C) International Society of Behavioral Medicine 2009

Erratum to: Int. J. Behav. Med.

DOI 10.1007/s12529-009-9059-z

In the original publication, the affiliation of Andrea W. M. Evers was incorrectly captured. Where is written "University of Nijmegen" should read "Radboud University Nijmegen."

The online version of the original article can be found at http://dx.doi. org/10.1007/s12529-009-9059-z.

E. Lauwerier $\cdot$ G. Crombez $(\bowtie) \cdot S$. Van Damme $\cdot$ L. Goubert Department of Experimental-Clinical and Health Psychology,

Ghent University,

Henri Dunantlaan 2,

9000 Ghent, Belgium

e-mail: Geert.Crombez@UGent.be

D. Vogelaers

General Internal Medicine and Infectious Diseases,

Ghent University Hospital,

Ghent, Belgium

A. W. M. Evers

Department of Medical Psychology,

Radboud University Nijmegen,

Nijmegen, the Netherlands 